\title{
Wisconsin Twin Panel
}

\author{
Carol A. Van Hulle', Kathryn S. Lemery ${ }^{2}$, and H. Hill Goldsmith ${ }^{3}$ \\ 'Department of Psychology, University of Wisconsin, Madison, WI, USA \\ ${ }^{2}$ Arizona State University, Tempe, AZ, USA \\ ${ }^{3}$ Department of Psychology, University of Wisconsin, Madison, WI, USA
}

\begin{abstract}
The Wisconsin Twin Panel was initiated in 1994 to serve a study of the development of childhood mood and behavioral disorders. Families who give birth to twins within the state of Wisconsin are recruited within 6 months of the birth. The panel currently supports three ongoing, longitudinal research projects. Research foci include studying epigenetic contributions to emotional, physical, cognitive, and motoric development of infant and toddler twins; physiological concomitants of childhood temperament; and early risk and resiliency factors related to child psychopathology. All three studies include videotaped observational assessments and biological measures.
\end{abstract}

The Wisconsin Twin Panel (WTP) was initiated in 1994 with the goal of studying the etiology and development of childhood mood and behavioral disorders. The panel is part of the Center for Affective Science, a multi-disciplinary center dedicated to studying aspects of emotion and emotional development, and is housed in the biobehavioral research unit at the Waisman Center, University of Wisconsin-Madison.

WTP was intended as a means of identifying a large, representative sample of young twins to study early factors related to both risk and resiliency. We actively recruit all twins born in the state of Wisconsin from state birth records within 6 months of birth, including opposite-sex twins. Families that live within one-hour driving distance from the university ( $1 \frac{1}{4}$ of the sample) are then invited to participate in the extensive Genetics of Emotional Ontogeny (GEO) twin project (which has six primary measurement occasions over the course of the first three years of life). Families that live too far or do not wish to participate in the in-depth GEO project are first assessed when the twins turn 2 years of age.

\section{Recruitment}

Approximately 750 twin births occur each year in Wisconsin. Parents are contacted within 6 months of birth and asked if they would like to participate in twin studies. In general, between 60 and $80 \%$ of families respond to the initial letter of invitation, and $80-85 \%$ of these respond favorably. Six weeks after the initial contact, a second letter is sent reminding parents to reply. Another 10-15\% responded favorably to the second letter. A final effort is made to call the remaining parents who have not responded. Approximately $70 \%$ of those contacted by phone agree to participate. (When we created the panel in
1994, we recruited twins born in the years 1989-1994 simultaneously.) We plan to continue adding new families to the twin panel indefinitely to support twin research.

\section{Overview of WTP Research Projects}

Currently, the panel is serving three main projects. All phases of these projects are presently ongoing. Firstly, the GEO project of epigenetic contributions to infant and toddler development, mentioned above. Secondly, a longitudinal follow-up of the GEO families at 7 years of age. This follow-up incorporates laboratory psychophysiological (EEG, heartrate, vagal tone) and hormone (salivary cortisol) measurement in addition to observational and caregiver report of temperament. DNA is also collected from the twins at this time. The third project is the most extensive and makes use of all panel families living throughout the state. Its focus is early risk for child psychopathology, and it includes three longitudinal phases at 2, 6, and 7 years. This project will be described in more depth and serve as an example of our multi-trait/multi-method designs.

\section{Risk for Child Psychopathology Research Design}

Table 1 summarizes the assessment at each phase. Whereas all WTP families are invited to participate in Phases One and Two, the extensive battery of assessments at Phase Three involves children classified into one or more risk groups (internalizing, externalizing, and/or attention problems) or a control group (children who are low on all risk scales), detailed below.

The main goals of this project are as follows:

1. To identify and assess a sample of 6- to 8-year-old twins at risk for internalizing, externalizing, and attentional disorders.

2. To assess these twins, as well as their co-twins, with instruments designed to characterize their behavioral problems and risk factors more fully with a structured interview, additional parental report measures and behavioral assessments.

3. To screen the parents and other siblings for psychopathology.

Address for correspondence: Carol A. Van Hulle, Department of Psychology, University of Wisconsin, 1202 W. Johnson St., Madison,WI 53706-1696,USA. Email: cavanhulle@facstaff.wisc.edu 
4. To assess the twins' environment to possibly identify features associated with risk.

5. To estimate the genetic influence on (a) the measures of the risk factors; (b) the disorders themselves; and (c) the association between the risk factors and the disorders. There are many facets to this goal. For instance, if temperamental shyness proves to be a risk factor for internalizing disorders of childhood, we can ask (a) if association between shyness and internalizing disorder is genetically mediated; (b) if the disorder can be viewed, genetically, as simply an extreme of the shyness dimension; or, alternatively, (c) whether the association of shyness and internalizing disorder is environmentally mediated, which would then encourage a search for environmental risk factors.

6. To consider possible risk-reducing factors related to resiliency and adaptability, such as the capacity to experience and express pleasure.

7. To lay the foundation for a follow-up when the twins have lived through more of the risk period for onset of the disorders.

\section{Table 1}

Risk for Child Psychopathology Twin Study: Overview of Assessments.

Phase I

1. Mother report, Zygosity Questionnaire for Young Twins (Goldsmith, 1991)

2. Mother report, family demographics

3. Mother report, Toddler Behavior Assessment Questionnaire (TBAQ; Goldsmith, 1996)

4. Mother \& father report, Infant-Toddler Social and Emotional Assessment (ITSEA; Briggs-Gowan \& Carter, 1998)

5. Mother \& father report, Child Rearing Practices Report (CRPR; Block, 1965)

6. Mother report, MacArthur Communicative Development Inventory (short form) (CDI; Fenson et al., 2000)

Phase II

1. Mother \& father report, Health and Behavior Questionnaire (HBO; Ablow et al., 1999)

2. Mother \& father report, Children's Behavior Questionnaire (CBO; Rothbart et al., 2001)

3. Mother \& father report of family demographics

Phase III

Twin Measures

1. Diagnostic Interview Schedule for Children (DISC-IV; Fisher, 1997)

2. Mother \& father report, Health and Behavior Questionnaire (HBO; Ablow et al., 1999)

3. Self report, Berkeley Puppet Interview (BPI; Ablow et al., 1999)

4. Laboratory Temperament Assessment Battery (Lab-TAB; Goldsmith et al., 1993)

5. Peabody Picture Vocabulary Test — Revised (PPVT; Dunn \& Dunn, 1981)

6. Block Design subtest of the WISC-III (Wechsler, 1991)

7. Mother \& father report, Children's Behavior Questionnaire (CB0; Rothbart et al., 2001)

8. Child tester observer ratings

9. Multi-day basal cortisol and reactive cortisol during and after the home visit

10. DNA for candidate gene studies

Other Family Members

1. Mother \& father report, Composite International Diagnostic Interview (CIDI; Robins et al., 1988)

2. Mother report of other siblings, Health and Behavior Questionnaire (HBO; Ablow et al., 1999)

3. Mother \& father report, Beck Depression Inventory (BDI; Beck et al., 1961)

4. Mother \& father report, Multidimensional Personality Questionnaire (MPO; Tellegen, 1978/82)

5. Mother \& father report, Positive \& Negative Affect Schedule (PANAS; Watson et al., 1988)

6. Mother, father, \& other sibling multi-day basal cortisol

7. Mother, father \& other sibling DNA

Relationship and Family Environment Measures

1. Twin Dyadic Interactions

2. Parent/Twin Triadic Interactions

3. Twin self report, Sibling Relationship Questionnaire (SR0; Furman \& Buhrmester, 1985)

4. Twin self report BPI (Ablow et al., 1999)

5. Mother report, Sibling Relationship Scale (SRS; Hembree, 1996)

6. Child tester observer ratings

7. Twin, mother, \& father report, differential treatment of twins

8. Mother report, Family Adjustment Scale (FAS; Epstien et al., 1983)

9. Mother report, Dyadic Adjustment Scale (DAS; Spanier, 1976)

10. Mother report, Family Conflict Survey (Porter \& O'Leary, 1980)

11. Mother report, Parenting Stress Index (PSI; Burke \& Abidin, 1978)

12. Mother \& father report, Child Rearing Practices Report (CRPR; Block, 1965)

13. Mother \& father report, Behavioral Management Self-Assessment (BMSA)

14. Mother report, Confusion, Hubbub, and Order Scale (CHAOS; Matheny et al., 1995)

15. Mother report, Family Inventory of Life Events (FILE; McCubbin, Patterson, \& Wilson, 1981)

16. Interviewer report, Living Environment Observation Scale (HOME; Caldwell \& Bradley, 1979)

17. Pregnancy and birth records

18. Twin palmar asymmetries 
8. To collect and store DNA samples for future analyses once more potential markers of the disorder and more genes involved in relevant neural system functioning are identified.

Phase I occurs when the twins turn 2 years of age. The twins' mother is interviewed over the telephone and a packet of questionnaires is sent to the home with questions for both the mother and father to complete. The focus of the assessment is early temperament and mood/behavior problem symptoms; those measured are outlined in Table 1.

Phase II takes place when the twins reach 6 years of age. At this time, both mothers and fathers complete a packet of questionnaires that again tap temperament and mood/behavior problem symptoms. Of those contacted, typically $90-95 \%$ agree to participate.

The main thrust of the project takes place during Phase III. This phase begins within a year of phase II when the twins are approximately 7 years old. The primary caregiver is contacted over the telephone and the mood/behavior disorder symptom questions from the Health and Behavior Questionnaire (HBQ; Ablow et al., 1999) are administered to screen the sample for twins displaying symptoms of child psychopathology. From this screener, three at-risk groups are formed: internalizing, externalizing, and attention problems. Families enter a risk group if at least one of their twins scores high (1.5 SD above the mean) on a symptom composite, or any subscale that is incorporated into the composite (such as depression, separation anxiety, or overanxious disorder for the internalizing composite). Under these criteria, about $75-85 \%$ of those identified as at-risk receive a diagnosis on the Diagnostic Interview Schedule for Children (DISC-IV; Fisher, 1997). To be included in the comparison group the individual must be below the mean on all symptom scales. Approximately $95 \%$ of families recruited for Phase III agree to participate. Of those families who participate in the screening, $27 \%$ qualify as atrisk families and $25 \%$ qualify as comparison families.

Twins selected into the risk groups or control group, and their co-twins, are assessed in their homes during a five hour visit. Prior to the home visit, parents are interviewed via telephone and administered a variety of questionnaires assessing the family environment, family conflict, discipline, parental attitudes, and parent temperament. See Table 1 for a list of the Phase III assessments.

One of the many observational measures used is the extensive Laboratory Temperament Assessment Battery (Lab-TAB; Goldsmith et al., 1993), modified for use in the home with seven year olds. Lab-TAB is a set of standardized procedures for eliciting behavior in the following domains: social fear/inhibition, anger/frustration, sadness, exuberance, contentment, activity, persistence, inhibitory control, empathy, and compliance. Episodes are videotaped for later coding of the latency, peak intensity, and duration of each emotional response.

During the home visit, the primary caregiver is administered a structured clinical interview separately for each twin, the DISC-IV. In addition, she is asked to complete a set of questionnaires detailing aspects of the home environment (both shared and non-shared environments, family history, and sibling relationships). Parents also complete the HBQ for each of the twins' other siblings living in the home. Children's self-reported behavior (peer relations, externalizing and internalizing behaviors) is obtained using the Berkeley Puppet Interview (Ablow et al., 1999). Finally, the testers make post-visit ratings of the children's temperament, mood/behavior, problem behaviors, and home environment. In addition to the behavior measures, DNA and cortisol are obtained from all family members, including any siblings between the ages of 5 and 18 years. Salivary cortisol samples are taken late in the afternoon (4-6 p.m.) and evening (just before bed) on three consecutive days. Also, "reactive" cortisol is obtained from the twins during the home visits. Salivary cortisol is obtained at the beginning of the visit, 45 minutes into the visit (approximately 20-30 minutes after a stressor), and at the end of the visit. DNA is obtained from buccal cells from all family members.

WTP research projects currently follow children through age 7 , but there are plans to extend the longitudinal assessments through adolescence. Future potential collaborations for follow up studies of this sample are welcome. Please contact Hill Goldsmith.

\section{Footnote}

1 Please direct any questions concerning the Wisconsin Twin Panel to H. Hill Goldsmith, Department of Psychology, University of Wisconsin 1202 W. Johnson St., Madison, WI 53706-1696, USA. Email: hhgoldsm@facstaff.wisc.edu.

\section{$\overline{\text { References }}$}

Ablow, J., Measelle, J. R., Kraemer, H. C., Harrington, R., Luby, J., Smider, N. et al. (1999). The MacArthur three-city outcome study: Evaluating multi-informant measures of young children's symptomatology. Journal of the American Academy of Child and Adolescent Psychiatry, 38, 1580-1590.

Beck, A. T., Ward, C. H., Mendelson, M., Mock, J. E., \& Erbaugh, J.K. (1961). An inventory for measuring depression. Archives of General Psychiatry, 4, 561-571.

Block, H. J. (1965). The child rearing practices report (Tech. Rep.). Berkeley: Institute of Human Development, University of California.

Briggs-Gowan, M. J., \& Carter, A. S. (1998). Preliminary acceptability and psychometrics of the Infant \& Toddler Social and Emotional Assessment (ITSEA): A new adult-report questionnaire. Infant Mental Health Journal, 19, 422-445.

Burke, W. T., \& Abidin, R. R. (1978). The development of a parenting stress index. Paper presented at the American Psychological Association Conference, Montreal.

Caldwell, B., \& Bradley, R. (1978). Manual for the Home Observation for Measurement of the Environment. Little Rock: University of Arkansas.

Dunn, L. M., \& Dunn, L. M. (1981). Peabody Picture Vocabul.ary Test - Revised. Circle Pines, MN: American Guidance Service.

Epstein, N. B., Baldwin, L. M., \& Bishop. D. S. (1983). The McMaster Family Assessment Device. Journal of Marital and Family Therapy, 9, 171-180.

Fenson, L., Pethick, S., Renda, C., Cox, J., Dale, P., \& Reznick, J. S. (2000). Short-form versions of the MacAurthur Communicative 
Development Inventories. Applied Psycholinguistics, 21, 95-115.

Fisher, P. (1997). Diagnostic Interview Schedule for Children, Version IV: Test-retest reliability in a clinical sample. Paper presented at the 44th Annual Meeting of the American Academy of Child and Adolescent Psychiatry, Toronto.

Furman, W., \& Buhrmester, D. (1985). Children's perceptions of the qualities of sibling relationships. Child Development, 56, 448-461.

Goldsmith, H. H. (1991). A zygosity questionnaire for young twins: A research note. Behavior Genetics, 21, 257-269.

Goldsmith, H. H. (1996). Studying temperament via construction of the Toddler Behavior Assessment Questionnaire. Child Development, 67, 218-235.

Goldsmith, H. H., Reilly, J., Lemery, K. S., Longley, L., \& Prescott, A. (1993). The Laboratory Temperament Assessment Battery (Lab-TAB): Preschool version (Tech. Rep.). Madison WI: University of Wisconsin-Madison.

Hembree, S. (1996). Parental contributions to young children's sibling relationships. Unpublished doctoral dissertation, University of Wisconsin, Madison, WI.

Matheny, A. P., Wachs, T. D., Ludwig, J. L., \& Phillips, K. (1995). Bringing order out of chaos: Psychometric characteristics of the Confusion, Hubbub, And Order Scale (CHAOS). Journal of Applied Developmental Psychology, 16, 429-444.
McCubbin, H. I., Patterson, J. M., \& Wilson, L. (1981). Family Inventory of Life Events and Changes (Tech. Rep.). St. Paul: University of MN.

Porter, B., \& O'Leary, K. D. (1980). Marital discord and childhood behavior problems. Journal of Abnormal Psychology, 9, 191-202.

Robins, L. N., Wing, J., Wittchen, H. U., Helzer, J. E., Babor, T. F., Burke, J. et al. (1988). The Composite International Diagnostic Interview: An epidemiological instrument suitable for use in conjunction with different diagnostic systems and in different cultures. Archives of General Psychiatry, 44, 1069-1077.

Rothbart, M. K., Ahadi, S. A., Hersey, K. L., \& Fisher, P. (2001). Investigations of temperament at three to seven years: The Children's Behavior Questionnaire. Child Development. 72(5), 1394-1408.

Spanier, G. B. (1976). Measuring dyadic adjustement: New scales for assessing the quality of marriage and similar dyads. Journal of Marriage and the Family, 38, 15-28.

Tellegen, A. (1978/82). A Brief Manual of the Multidimensional Personality Questionnaire. Unpublished manuscript, University of Minnesota.

Watson, D., Clark, L. A., \& Tellegen, A. (1988). Development and validation of brief measures of positive and negative affect: The PANAS Scales. Journal of Personality and Social Psychology, 54, 1063-1070.

Wechsler, D. (1991). WISCIII: Wechsler Intelligence Scale for Children - Third Edition. Orlando: Harcourt Brace. 